\title{
Clinical Outcome of Autologous Serum Therapy in Chronic Idiopathic Urticaria
}

\author{
Dharmendra Karn, ${ }^{1}$ Shekhar KC \\ ${ }^{1}$ Department of Dermatology, Dhulikhel Hospital, Kavre, Nepal.
}

\begin{abstract}
Background: Quality of life in chronic idiopathic urticaria is hampered as efficacy of H1-antihistamines is limited.
Autologous serum containing tolerance-generating anti-idiotype antibodies is a novel and cost-effective therapy. This
study was conducted to evaluate the efficacy of autologous serum therapy (AST) among chronic urticaria patients with
autologous skin prick test positive and negative status.
Methods: Untreated 102 patients of chronic urticaria were enrolled in a non-randomized interventional study.
Patients were categorized into two groups based on autologous serum skin prick test as test positive (ASST + ) and test
negative (ASST -). Patients were then treated with intramuscular injection of 0.05 ml per kg body weight of autologous
serum weekly for 10 weeks. Urticaria activity scoring (UAS) tool was used for quantification of the symptoms. Weekly
recording of UAS (range: $0-42$ ) was made before the therapy (baseline) and during the therapy for 10 weeks.
Results: Significant improvement with AST in the mean UAS was noted from baseline to 10 weeks in both the group
of patients (14.6 \pm 6.3 and $10.2 \pm 5.1$ for ASST + group ; $16.9 \pm 7.8$ and $8.6 \pm 4.8$ for ASST- group; at baseline and
10 weeks, respectively (p-value for both $<0.05$ )). However no statistical significance was found while comparing the
efficacy of the therapy against ASST + and ASST - Groups (p-value $>0.05$ ).
Conclusions: Irrespective of autologous skin prick test results, autologous serum therapy showed significant
improvement in patients with chornic idiopathic urticaria. AST can, thus, be an effective treatment modality for it.
Keywords: Autologous serum skin prick test; autologous serum therapy; chronic urticaria.
\end{abstract}

INTRODUCTION

Chronic urticaria (CU) is defined as "itchy urticarial wheals present on most of the days for six weeks, and a single wheal resolving spontaneously within 24 hours" 1,2 The course of $\mathrm{CU}$ is unpredictable and may last for years. Quality of life further deteriorates as the symptoms flare up following withdrawal of antihistamines. ${ }^{3}$

Autologous serum containing tolerance-generating antiidiotype antibodies against mast cell degranulating antigens is a novel therapy for patients with chronic idiopathic urticaria $(\mathrm{ClU}) .{ }^{4}$ It helps to reduce the pill burden and improve the quality of life. Auto reactive circulating antibodies have been detected in 30-60\% patients with CU. ${ }^{5,6}$ Expression of antibodies against the high affinity receptor for IgE (anti-Fc $\mathrm{RI}_{\varepsilon}$ ) of mast cells or $\operatorname{lgE}$ (anti-lgE) is the basis for AST.

The efficacy of AST in autoreactive and non-autoreactive urticaria patients is not known. The present study intends to compare the clinical efficacy of autologous serum therapy between autologous serum reactive and non-reactive cases. Provided the efficacy remains better in both subset of patients; AST would be a cost-effective and efficacious modality of treatment for patients of CIU.

\section{METHODS}

This was a cross-sectional, non-randomized, single centre, interventional study from January 2014 till December 2015 at the dermatology outpatient of Dhulikhel Hospital Kathmandu University Hospital involving patients of chronic urticaria. Ethical approval was obtained from the institutional review board Kathmandu University School of Medical Sciences (IRB ref no.: 57/13). Written informed consent was taken from patients prior to enrollment. Patients of age less than 16 years and greater than 50 years, patients with a known etiology for urticaria, pregnant or lactating, diabetes mellitus and patients under any other forms of systemic medications for past one month (washout period) were excluded from the study.

Probable etiology of urticaria was ruled out following detailed history regarding any environmental, food or drug as a trigger, probable cause for physical urticaria, 
diurnal variation or history of contact with any allergen for contact urticaria. Examination and laboratory parameters included complete blood count, erythrocyte sedimentation rate, anti-nuclear antibodies, thyroid function test, anti-streptolysin 0 titre, urine and stool routine examination for infection or infestation related urticaria.

Patients were then subjected to autologous serum skin test (ASST). Prior confirmation was done that patients had not taken antihistamines for at least one week. The test was performed by drawing $5 \mathrm{~mL}$ of venous blood from the anti-cubital vein. It was stored in a plane unheparinized sterile plastic tube so that the blood clots at room temperature. The serum was then extracted by centrifuging the blood for 10 minutes at 2000 revolutions per minute. A volume of $0.05 \mathrm{~mL}$ of the patient's serum was injected intradermally on volar aspect of the patient's forearm at a site not previously affected by a wheal in the last 24 hours. A positive test control was done with $0.1 \%$ histamine solution and negative control was done using $0.9 \%$ isotonic saline. Readings were taken after 20 minutes for the reactive wheals.

Patients were categorized into two groups based on reactivity as autologous serum skin prick test as test positive (ASST +) and test negative (ASST-). Patients were then treated with weekly intramuscular injection (Gluteus muscle) of $0.05 \mathrm{ml}$ per kg body weight freshly prepared autologous processed serum for 10 weeks. For clinical outcome, weekly urticaria activity scoring (UAS-7) tool (Table 1) was used for the quantification of response in terms of number of wheals and pruritus. ${ }^{7} \mathrm{~A}$ baseline (before the therapy) and weekly assessment of the score was done during the 10 weeks of therapy as studied by Debberman et al. ${ }^{8}$

No other forms of therapeutic treatment were allowed during the treatment and follow up period.

Follow up period was weekly up to 10 weeks for therapy and at 14 week from baseline. Weekly urticaria activity score (UAS7) was recorded for evaluation of efficacy. Patients having no symptoms (UAS7 value zero) were considered to have complete resolution. An adverse clinical effect was not expected as patient's own serum was being used for the therapy. Any apparent adverse clinical effects were recorded. Student's t-test was used where equal variance was demonstrated. Chi square test was used for categorical variables.

\section{RESULTS}

A total of 102 patients were evaluated during the study period. There were 37 patients (36.2\%) demonstrating reactivity with autologous serum (ASST+) and 65(63.8\%) had no reactivity (ASST-). The demographical and disease related data of patients is shown in Table 2.

\begin{tabular}{|c|c|c|}
\hline Score & Wheals & Pruritus \\
\hline 0 & None & None \\
\hline 1 & $\begin{array}{l}\text { Mild }(<20 \\
\text { wheals/24hr) }\end{array}$ & $\begin{array}{l}\text { Mild (present but not } \\
\text { annoying or troublesome) }\end{array}$ \\
\hline 2 & $\begin{array}{l}\text { Moderate } \\
(20-50 \\
\text { wheals/24hr) }\end{array}$ & $\begin{array}{l}\text { Moderate (troublesome } \\
\text { but does not interfere } \\
\text { with normal daily activity } \\
\text { or sleep) }\end{array}$ \\
\hline 3 & $\begin{array}{l}\text { Intense }(>50 \\
\text { wheals } / 24 \\
\text { hr or large } \\
\text { confluent areas } \\
\text { of wheals) }\end{array}$ & $\begin{array}{l}\text { Intense (severe pruritus, } \\
\text { which is sufficiently } \\
\text { troublesome to interfere } \\
\text { with normal daily activity } \\
\text { or sleep) }\end{array}$ \\
\hline
\end{tabular}

The female: male of CIU was 2.3: 1. Variables including age, gender, duration of disease and associated angioedema did not affect the reactivity of ASST. A statistically significant decrease was seen in the overall UAS score from baseline to 10 weeks in both the groups (Table 3). However, no difference was evident between the therapeutic outcomes of two groups $(p=0.11)$. Figure 1 shows the weekly change in the UAS score during the therapy.

\begin{tabular}{|c|c|c|c|}
\hline Variables & $\begin{array}{l}\text { ASST+ } \\
(n=37)\end{array}$ & $\begin{array}{l}\text { ASST- } \\
(n=65)\end{array}$ & $\mathrm{p}$-value \\
\hline Age (Years) & $22.5 \pm 9.7$ & $25.2 \pm 11.2$ & 0.22 \\
\hline \multicolumn{4}{|l|}{ Gender } \\
\hline Male & 12 & 19 & \multirow{2}{*}{0.73} \\
\hline Female & 25 & 46 & \\
\hline \multicolumn{4}{|l|}{$\begin{array}{l}\text { Duration of } \\
\text { disease }\end{array}$} \\
\hline$<6$ months & 24 & 36 & \multirow{2}{*}{0.34} \\
\hline$>6$ months & 13 & 29 & \\
\hline $\begin{array}{l}\text { Mean duration } \\
\text { of symptoms } \\
\text { (Months) }\end{array}$ & $12.9 \pm 10.84$ & $\begin{array}{l}16.3 \pm \\
14.86\end{array}$ & 0.22 \\
\hline Associated & & & \\
\hline \multicolumn{4}{|l|}{ Angioedema } \\
\hline Yes & 30 & 53 & 0.95 \\
\hline \multicolumn{4}{|l|}{$\begin{array}{l}\text { No } \\
\text { Daily use of } \\
\text { antihistamine } \\
\text { tablet }\end{array}$} \\
\hline Yes & 19 & 39 & \multirow{2}{*}{0.39} \\
\hline No & 18 & 26 & \\
\hline
\end{tabular}

At 14 weeks follow-up, 14 patients (37.8\%) from ASST+ group and 22 patients (33.8\%) from ASST- group had complete resolution of symptoms. Pain during the intramuscular injection was the only adverse clinical event reported during the study period. 
Table 3. Comparison between baseline and 10 weeks' urticaria activity score.

\begin{tabular}{|c|c|c|c|}
\hline Group & Baseline UAS & 10 weeks UAS & p-value \\
\hline ASST $+(n=37)$ & $14.6 \pm 6.3$ & $10.2 \pm 5.1$ & 0.0015 \\
\hline ASST - $(n=65)$ & $16.9 \pm 7.8$ & $8.6 \pm 4.8$ & 0.0001 \\
\hline
\end{tabular}

ASST: autologous serum skin test; UAS: urticaria activity score

Table 4. Comparison of related articles in autologous serum therapy.

\begin{tabular}{|c|c|c|c|c|}
\hline S.N. & Study & $\begin{array}{l}\text { No. of } \\
\text { patients }\end{array}$ & Scale used & Conclusion \\
\hline 1 & Bajaj et al. ${ }^{10}$ & 75 & Total Severity Score & $\begin{array}{l}\text { AST is effective among ASST+ } \\
\text { subjects and smaller but substantial } \\
\text { number of ASST- subjects }\end{array}$ \\
\hline 2. & Staubach et al. ${ }^{9}$ & 56 & $\begin{array}{l}\text { CU activity } \\
\text { Antitihistamine use } \\
\text { Quality of life }\end{array}$ & $\begin{array}{l}\text { ASST+ and not ASST- patients can } \\
\text { benefit from Aotologous whole blood } \\
\text { therapy. }\end{array}$ \\
\hline 3. & Debbarman et al. ${ }^{8}$ & 54 & $\begin{array}{l}\text { Total severity score, } \\
\text { Urticaria activity score, } \\
\text { Dermatologic life quality index }\end{array}$ & $\begin{array}{l}\text { Regardless of the autoreactive } \\
\text { nature, AST is better in CU. }\end{array}$ \\
\hline
\end{tabular}

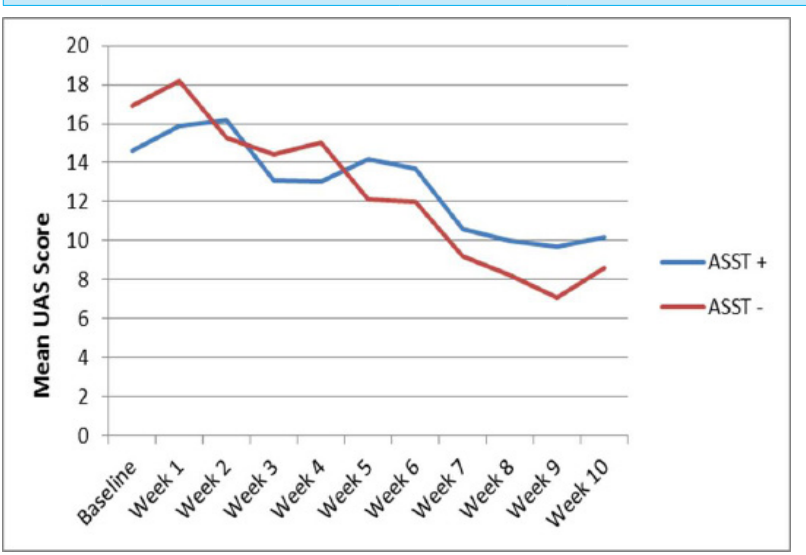

Figure 1: Weekly change in mean urticaria activity score.

\section{DISCUSSION}

Chronic urticaria is a disabling morbidity and differentiation of chronic idiopathic urticaria into autoimmune or non-autoimmune patients is difficult to elicit from history and clinical examination. ${ }^{1,2}$ Autologous serum skin testing (ASST) offers this advantage. The present study has shown that $37(36.2 \%)$ patients had developed significant $(>1.5 \mathrm{~mm})$ wheals to autologous serum. Prevalence of this autoreactive phenomenon has been described in 27-61\% cases of CIU. ${ }^{4,5}$ This finding is similar to other studies from Bajaj et al. (49.5\%), Hayder et al. (40.7\%) and Debbarman et al. (40.5\%). ${ }^{7,9,10}$ The principle of this in-vivo test relies on circulating autoreactive endogenous pro-inflammatory or whealinducing factors. ${ }^{4-6}$ Antibodies to high-affinity IgE receptor ( $\mathrm{Fc \varepsilon RI})$ is thought to cross link the IgE receptors hence causing mast cell degranulation.
Patients with positive ASST are supposed to have more severe and prolonged disease, frequent attacks and higher serum IgE levels. Patients with positive ASST have been linked to HLADR4, other autoimmune diseases, prolonged disease course and less susceptibility to $\mathrm{H} 1$ antihistamines. Autoimmune disorders as thyroiditis, lupus erythematosus, pernicious anemia, diabetes mellitus, alopecia areata and myasthenia gravis could be linked to such autoreactive phenomenon. A higher prevalence of autoimmune disorders among females including $\mathrm{CIU}$ as in the present study could be attributed to hormonal factors.

Staubach et al. had concluded that these two groups are identical in various clinical and serological parameters including number, size, intensity, quality of life and expression of anti-Fc(epsilon)RI or anti-IgE. ${ }^{9}$ However, patients with autoreactive urticaria were of longer duration and required markedly more antihistaminic medicine. Similarly, these groups were also not identical in terms of age, severity score, duration of individual wheals, presence of family history, presence of personal and/or family history of atopy or of autoimmune diseases. ${ }^{7,11}$ In the present study as well there were no significant differentiation between the two groups including duration of symptoms and frequency of antihistamine drug. One advantage of performing ASST could be a prognostic counseling and early use of immunomodulatory agents among ASST positive patients.

Autologous serum therapy has been a novel therapeutic modality of treatment for CIU. Induction of antiidiotype and shifting of Th2 cytokine profile to Th1 has 
been the postulated mechanism of autologous serum therapy. ${ }^{10}$ The present study has shown efficacy of AST in both groups irrespective of ASST reactivity (Table 3). Pubmed and Medline search of related articles relating evaluation of autologous serum therapy among patients of autologous serum skin test was done. Three relevant studies demonstrated varying results regarding efficacy of AST among patients with autoreactive and non-reactive forms of CIU (Table 4). The conclusion still remains unclear. Some authors have suggested that autoreactivity is not an all or none phenomenon. ${ }^{7,10}$ It perhaps reflect a reactive state to multiple and unknown circulating factors. For instance, a positive autologous serum test has been demonstrated in subjects with positive Helicobacter pylori antigen. ${ }^{12}$ It is possible that the ASST-negative patients possess a different IgG subclass with decreased ability to release histamine from basophil activation.

\section{CONCLUSIONS}

Autologous serum skin test is a simple, office based test to diagnose subset of patients with CIU having autoimmunity. Autologous serum therapy has shown efficacy in patients with CIU irrespective of autologous skin prick test results.

\section{REFERENCES}

1. Borges MS, Asero R, Ansotegui IJ, Baiardini I, Bernstein JA, Canonica GW, et al. Diagnosis and Treatment of Urticaria and Angioedema: A Worldwide Perspective. World Allergy Organ J. 2012;5:125-47. [PubMed]

2. Goh CL, Tan KT. Chronic autoimmune urticaria: where we stand? Indian J Dermatol. 2009;54:269-74. [PubMed]

3. Soter NA. Treatment of urticaria and angioedema: lowsedating H1-type antihistamines. J Am Acad Dermatol. 1991;24:1084-7. [PubMed]

4. Hide M, Francis DM, Grattan CE, Hakimi J, Kochan JP,
Greaves MW. Autoantibodies against the high affinity IgE receptor as a cause of histamine release in chronic urticaria. N Engl J Med. 1993;328:1599-604. [PubMed]

5. Piconi S, Trabattoni D, Lemoli E, Fusi ML, Villa ML, Milazzo F, et. al. Immune profiles of patients with chronic idiopathic urticaria. Int Arch Allergy Immunol. 2002;128:59-66. [Link]

6. Cho CB, Stutes SA, Altrich ML, Ardoin SP, Phillips G, Ogbogu PU. Autoantibodies in chronic idiopathic urticaria and nonurticarial systemic autoimmune disorders. Ann Allergy Asthma Immunol. 2013;110:29-33. [PubMed]

7. Mlynek A, Zalewska-Janowska A, Martus P, Staubach P, Zuberbier T, Maurer M. How to assess disease activity in patients with chronic urticaria? Allergy. 2008;63:777-80. [PubMed]

8. Debbarman P, Sil A, Datta PK, Bandyopadhyay D, Das NK. Autologous Serum Therapy in Chronic Urticaria: A Promising Complement to Antihistamines. Indian J Dermatol. 2014;59:375-82. [PubMed]

9. Staubach P, Onnen K, Vonend A, Metz M, Siebenhaar F, Tschentscher I, et al. Autologous whole blood injections to patients with chronic urticaria and a positive autologous serum skin test: A placebo-controlled trial. Dermatology 2006;212:150-9. [PubMed]

10. Bajaj AK, Saraswat A, Upadhyay A, Damisetty R, Dhar S. Autologous serum therapy in chronic urticaria: Old wine in a new bottle. Indian J Dermatol Venereol Leprol. 2008;74:109-13. [PubMed]

11. Hayder R. Al-Hamamy, Hameed AF, Abdulhadi AS. Autologous Serum Skin Test as a Diagnostic Aid in Chronic Idiopathic Urticaria. ISRN Dermatology. 2013:291524. [Link]

12. Baskan BE, Turker T, Gulten M, Tunali S. Lack of correlation between Helicobacter pylori infection and autologous serum skin test in chronic idiopathicurticaria. Int J Dermatol. 2005;44:993-5. [PubMed] 